\title{
Utilization of Internet Resources/Services by Academic Staff of National Water Resources Institute and Federal College of Forestry Mechanization, Kaduna, Kaduna State
}

\author{
Ikegwuiro Patience Uloaku \\ Information and Documentation Services Division, Department of Research and Technical Services, National Water Resources Institute, \\ Mando, Kaduna, Nigeria
}

Email address:

bankike@yahoo.com, patience@nwri.gov.ng

\section{To cite this article:}

Ikegwuiro Patience Uloaku. Utilization of Internet Resources/Services by Academic Staff of National Water Resources Institute and Federal College of Forestry Mechanization, Kaduna, Kaduna State. Advances in Sciences and Humanities. Vol. 3, No. 5, 2017, pp. 54-60.

doi: $10.11648 /$ j.ash.20170305.13

Received: June 3, 2017; Accepted: June 26, 2017; Published: October 23, 2017

\begin{abstract}
The study was undertaken to assess the Internet utilization by researchers in two selected special libraries in Kaduna state. The objectives of the study were to ascertain the type of Internet services that is provided in the special libraries; to know the purpose of using the internet by the researchers; to ascertain the particular Internet search engines researchers prefer to use to locate information on the Internet; to ascertain the degree of satisfaction with the use of Internet services by the researchers; to identify the challenges encountered while using the Internet by the researchers. Survey method of research was adopted. A total number of 102 copies of structured questionnaire were administered, out of which 88 were retrieved. Descriptive statistical tools such as simple percentages and tables were used to analyze the data. Findings of the study revealed that the Internet services mostly used by academic staff is e-mail services because it is important for every researcher to communicate their ideas or thoughts among them, and can send digital file to others as attachment. The study also revealed that the researcher use internet to search and obtain data for research and publication, access e-journals, sending and receiving emails etc. though some challenges were discovered to be a hindrance for effective utilization of the Internet by the researchers which include: slow internet service; internet connection failure; inadequate number of connected system. The study recommends that Efforts should be made to increase the speed of the Internet access and shorten the time it takes to view and download web pages by providing more bandwidths; Management of the institution should install internet services that will connect all the offices of the academic staff to enable them have access to internet facilities; More recent models computers should be provided and be connected to internet facilities in the libraries for patrons use; A maintenance programme should be put in place for regular maintenance, up-grading and repairs.
\end{abstract}

Keywords: Utilization, Internet Resources, Special Library, Information, Researchers

\section{Introduction}

The introduction of modern information technology has greatly changed the quality of work and activities in the libraries. It is becoming a vital component in the overall services and operations of library and information centers. Application of Internet and other network resources is changing the traditional library functions. Internet has become a basic ingredient of information accessibility and dissemination. According to Gbaje [1], the Internet is the network of networks linking millions of computer together. It has the ability and capability to provide adequate, current, and timely services to information seekers wherever they are. Internet is a network of millions of computer linked together with telecommunication equipment for the purpose of sharing data, resources and information. Agbaje [2] refers to Internet as a veritable tool for global online services. Internet availability has paved the way for some associated services in respect of serials such as browsing, e-mail, online system and information management. The use of the Internet in 
libraries and information centres makes available to the information user a wide range of learning resources available on the net especially the World Wide Web (www) and the electronic mail. In recent years, Internet and e-resources has emerged as a powerful educational information tools that has been spread technological literacy and given people all over the world fast access to vast resources [3]. Its availability has paved the way for some associated services in respect of serials such as browsing, e-mail, online system and information management.

Internet resources such as World Wide Web, e-mail, telnet, OPAC, search engines, File Transfer Protocol, digital collection, e-journal, chat group can be utilized by academic staff to enhance their research activities. Nwagwu et al [4] averred that the Internet serves as a source of information for literature review, authors search, subject search and research. Internet provides us with the means of carrying out research online by acting as the main engine for exchanging information especially among researchers [5]. Internet offers unprecedented access to information in all kind of formats. It brings advantages to its users in terms of searching for information, research, security and other related needs, in fact, that is why some universities and research institution established one form of Internet service or the other and researchers use Internet facilities regularly for their research work, leisure and discussions among others. With the rapid development and use of the Internet and web-based technology, publishing and distribution of information resources in digital format has become widespread [6]. The Internet has many benefits in the academic cycle including provision of round the clock access to a wide variety of information sources globally and the ability to discuss and share experience with colleagues.

A special library is a library maintained by an individual, corporation, association, government agency or any other group. It can also be defined as a specialized or departmental collection within a library for the organization and dissemination of information and primarily offering services to a specialized clientele through the use of varied media and methods [7].

To ensure that library services are given within the framework of users needs and in keeping with the aims and objective of that library, the application of Internet resources in special library is important.

\subsection{Statement of Problem}

There's no doubt that Internet plays a significant role in area of effective and efficient services in modern library. The introduction of the Internet technology has tremendously impacted on service delivery in libraries and information centres in the developed countries. In Nigeria, however, efforts are being made to strengthen the use of Internet particularly in library services delivery. Consequently, it is pertinent to investigate the use of Internet by researchers in special libraries in Kaduna. Although, various studies and observation indicates poor state of Internet application in some Libraries. Omosekejimi, Ijiekhuamhen and Emuejevoke [8] study indicates that Internet connectivity is not regular and not consistently available, and users are not satisfied with its use. In view of the few studies on the use of Internet by researchers in special libraries, it is imperative to carry out this investigation. The study is to find out the Internet resources/services that are used in special library services in Kaduna metropolis by researchers for their research activities as well as their satisfaction in using this internet, and the search engines used by the researchers in locating information on the Internet.

\subsection{Objective of the Study}

(1) To ascertain the type of Internet services that is provided in special libraries in Kaduna state

(2) To know the purpose of using the Internet by the researchers

(3) To ascertain the particular Internet search engines researchers prefer to use to locate information on the Internet.

(4) To ascertain the degree of satisfaction with the use of Internet services by the researchers.

(5) To identify the challenges encountered while using the Internet by the researchers.

\section{Literature Review}

\subsection{Internet Services and Resources Available for Special Libraries}

Internet services are the various services that are available in the Internet. In order to connect to the Internet, you need to use an Internet service. Internet services provide a way for data to be transferred from Internet servers to the computer. Components of the Internet are of different stages, which are interrelated and are backbone to its application. Muzakkari [9] asserted that Internet resources are the resources available in the net, which include: e-mail, chat groups, file transfer protocol, and so on.

Internet facilities such as e-mail, telnet, file transfer protocol, world wide web, Usenet, mailing list, can be used to enhance teaching and research. With such facilities, an academic staff can be able to have up-to-date information, know what is happening in his field of research somewhere around the globe, and share information with colleagues using the mailing list facility of the Internet [10]. Internet services are a major source by which library and information centres can effectively provide information services to its increasing population of users in this rapidly growing environment of information explosion and availability.

\subsection{Purpose of Using Internet by the Researchers}

Internet is a major source of knowledge and information. It is used to obtain vital resources for teaching and learning. Moman [11] evaluated the nature, extent, and satisfaction with the use of the Internet by Applied Science and 
Technology faculty in Jordan. He concluded that the Internet is widely used with emphasis on research and communication and was perceived as a very useful tool. In the same vein, [4] asserts that the Internet serves as a source of information for literature review, authors search, subject search and research. The study conducted by Aliyu [12] on use of Internet by academic scientists revealed that $92.59 \%$ of the academic scientist use the internet for communication and support of study purposes respectively, while $61.72 \%$ and $56.79 \%$ use it for professional research activities and recreation. Asemi [13] in his study on Internet use in academic libraries discovered that the researchers of the university were getting quality information through the Internet. $50 \%$ of the researchers search for scientific information through the internet.

The study of [8] on the accessibility and use of Internet facilities in University libraries revealed that $95.8 \%$ of the respondents admits that they use the Internet services to access newly publish information resources, $100 \%$ for research and academic development, and $65.6 \%$ and $56.5 \%$ affirm that they use it for their project work and article publishing respectively. Also, $65.9 \%$ admits that they use it for assignment purposes, while $57.1 \%$ of them agreed that they use Internet for exchange of ideas among colleagues via social networks.

\subsection{Search Engines Used by Researchers to Search and Locate Information in the Internet}

Accessing information is an important and essential skill inthe use of Internet by Libraries. According to Monereo, et al. [14] Search engines are system that can search the web using software robots/programmes for sites, read entire texts of the sites on the web, index them based on occurrence of the key words for each site, and enter them in database. In the same vein, Adesanya [15] opined that different types of search engines are available and work in different ways: some rely on people to maintain a catalogue of websites or pages; some use software to identify key information on sites across the Internet. These search engines includes: Google (http://www.google.com), $\quad$ Alta (http://www.altavista.com), Lycos (http:www.lycos.com), Excite (http://www.excite.com) AskJeeves (http://www.ask.com), Yahoo (http://www.yahoo.com), MSN (http://www.msn.com) etc.

Search engine are medium through which searches are successfully conducted. Madhusudhan [16] conducted a survey on Internet use by research scholars at Delhi University, which reveals that most respondents used search engines more than subject gateways or web directories to locate information. Asemi [13] findings revealed that Google search engines are mostly used by the respondents while searching for information on the Internet with $68 \%$, followed by Yahoo, AltaVista, MSN and HotBot with $61 \%, 15 \%, 11 \%$ and $4 \%$ preference respectively. The choice of Google and yahoo being that they are fast to access, information contained on these search engines are updated regularly and links are provided to websites in the world. Similarly, Devi and Singh [17] in their study found out that the respondents mostly use Google 79.3\%, followed by yahoo $39.2 \%$ and Rediff $25.6 \%$.

\subsection{Satisfaction Derived from Using the Internet by the Researchers}

Use of Internet in library services is believed to have had tremendous effect in libraries and to researchers in searching for information. Ojedokun [18] stated that the internet has many benefits in the academic cycle including provision of round the clock access to a wide variety of information sources globally and the ability to discuss and share experience with colleagues. Findings in a research conducted by Al-Ansari [19] revealed that academic staffs are satisfied with available Internet resources because it helped them to save time and find up-to-date information. Also Mohammed [20] found in his study on the use of ICT based resources and services in special libraries of kerala that a good number $56.4 \%$ of the library staff and $50 \%$ of users of state Government institution libraries were satisfied with the availability and application of ICT in their libraries.

Internet has helped for easy accessibility and dissemination of information. Many libraries have their catalogue of books and non-books in the web and accessibility to those catalogues is made easier and possible through Internet. According to Oketunji [21] the role of the Internet is to provide a way for researchers to have access to each other and to serve as a tool that facilitate their research. With the use of the Internet services like discussion groups, e-mail, it is possible to post message which include request for information: seeking book titles or reference materials, asking for names and addresses of people who have expert knowledge in particular areas. Aqil and Ahmad [22] conducted a survey at Aligarh Muslim University to find out the status of Internet based resources usage by the users. It was discovered that Internet based resources are the most satisfactory for the research scholars and post graduate students, the found it most satisfactory for their academic activities.

\subsection{Challenges Encountered While Using the Internet}

The Internet resources have improved the overall access to information by researchers world wide. However, their use by the researchers poses some challenges. Salaam [23] in his study on the use of Internet service in Nigerian University libraries found poor telecommunication system, unreliable electrical supply, lack of internet service providers in some parts of the country and poor funding of the university system as the major problems militating against access and use of internet facilities. Ishola et al [24] carried out a study on the availability, accessibility and use of e-resources in selected private universities. It shows that erratic power supply was one factor affecting its use $99.32 \%$; lack of adequate information, knowledge and retrieval skills $90.27 \%$; high cost of ICT $85.52 \%$ and lack of updated ICT strategy $59.04 \%$. The research conducted by [8] on the accessibility and use of Internet facilities in university libraries revealed 
that slow Internet service $95.8 \%$; internet connection failure $100 \%$; shortage of funds for Internet services, and unavailability of support for maintaining Internet facilities $62.8 \%$ as the challenges that hinders proper use of the Internet. Nwokedi [25] asserts that lack of searching skills, still militate good use of Internet. He stated that acquisition of Internet skills can lead to discovery of valuable research and teaching resources, which would in turn, causes the users to use the Internet to enhance their research, teaching and learning capabilities. The study by [5] on use of the Internet by researchers in agricultural research institutes shows that slow Internet connections $75.51 \%$ is the major challenge in their use of the Internet followed by inadequate browsing skill.

\section{Methodology}

Survey method was adopted in this study. According to Osuala [26] survey research studies a group of people or items by collecting and analyzing data from a sample considered being representative of the entire group under study. It helps to discover the relative incidence, distribution and interrelations of variables.

The survey method was also used for the work because the nature of the study itself warrants the use of the survey method as it enabled the researcher to reach out to the study population in their different locations.

The population of this study was limited to the special libraries that have Internet services in the libraries which users have access to. Two (2) special libraries are involved in this study. They are: National Water Resources Institute, Mando, and Federal College of Forestry Mechanisation, Afaka, all in Kaduna State. The academic staff in the two special libraries formed the population of the study. One hundred and two (102) were sampled for this research.

Questionnaire and observation were used as instrument for data collection in the study areas. According to Akuezuilo [27] posited that the survey researchers utilize instruments such as questionnaire, interview and direct observation in investigations. A well structured questionnaire with a cover letter was administered to the respondents. Its design reveals the bio-data and details of the five research questions which guided the course of this research. A total of eighty eight (88) questionnaires were adequately filled and used for the data analysis.

\section{Results and Findings}

The collected data were analyzed using descriptive statistics comprising of frequency distribution tables and simple percentages. The data are analyzed and discussed below.

\subsection{Internet Services Used in the Special Libraries of Kaduna State}

Table 1 shows analysis of data concerning this issue

Table 1. Internet services used in the special libraries of Kaduna state.

\begin{tabular}{llll}
\hline S/No & Internet services & Total & \\
\hline & & Freq & \% \\
\hline 1 & Electronic Mail (e-mail) & 85 & 96.6 \\
2 & World Wide Web (www) & 48 & 54.5 \\
3 & Online Database & 48 & 54.5 \\
4 & Internet chat/discussion groups & 21 & 23.9 \\
5 & E-journals & 71 & 80.7 \\
6 & Online Public Access Catalogue (OPAC) & 42 & 47.7 \\
7 & E-books & 40 & 45.5 \\
8 & Search Engine & 49 & 55.7 \\
9 & Own Website & 42 & 47.7 \\
10 & File Transfer Protocol & 3 & 3.4 \\
11 & Digital Collection/Archives & 38 & 43.2 \\
\hline
\end{tabular}

The findings from table 1 shows that the Internet resources/services that are mostly used by the respondents are electronic mail (e-mail) services with 85(96.6), e-journals 71(80.7), search engines 49(55.7\%), world wide web and online database $48(54.5 \%)$, Online public access catalogue and own website 42(47.7\%), e-books 40(45.5\%), Digital collection 3843.2), Internet chat/discussion group 21(23.9), and file transfer protocol 3(3.4).It is observed that the respondents do not explore the vast knowledge preserved in OPAC, Digital collections, and e-books. They use e- mail service more than others. This is because e-mail service is important for every researcher to communicate their ideas or thoughts among them and they can send digital files to others as attachment.

\subsection{The Purpose for Which Researchers Use Internet Services}

Table 2 shows the analysis of data pertaining to this issue

Table 2. The purpose for which researchers use Internet services.

\begin{tabular}{|c|c|c|c|}
\hline \multirow{2}{*}{ S/No } & \multirow{2}{*}{ Purpose of Using Internet } & \multicolumn{2}{|l|}{ Total } \\
\hline & & Freq & $\%$ \\
\hline 1 & To search and obtain data for research and publication & 86 & 97.7 \\
\hline 2 & To access electronic journals & 80 & 90.9 \\
\hline 3 & For sending and receiving e-mail & 86 & 97.7 \\
\hline 4 & To obtain routine information on conferences, seminars and job vacancies & 64 & 72.7 \\
\hline 5 & To access online newspapers & 58 & 65.9 \\
\hline 6 & To identify and approach experts in the field area & 16 & 18.2 \\
\hline 7 & To access books electronically & 44 & 50 \\
\hline 8 & To chat with friends and colleagues & 23 & 26.1 \\
\hline 9 & To use search engine to access information generally & 52 & 59.1 \\
\hline 10 & Downloading software & 8 & 9.1 \\
\hline
\end{tabular}


From table 3 above, $86(97.7 \%)$ of the total respondents admits that they use Internet mostly to search and obtain data for research and publication, and for sending and receiving e-mails;80(90.9) affirm that the use it to access electronic journals; $64(72.7 \%)$ indicates that the use it to obtain routine information on conferences, seminars and job vacancies; $58(65.9 \%)$ admits that they use it to access online newspaper; $52(59.1 \%)$ of the respondents says the use it for search engines to access information generally; $44(50 \%)$ indicates they use it to access books electronically; $23(26.1 \%)$ affirm that they use it to chat with friends and colleagues; and $8(9.1 \%)$ of the respondents says the use it to download software. This shows that the respondents use the Internet resources/services available in these libraries not only to search and obtain data for research and publication, but also for sending and receiving e-mail and other activities.

\subsection{Preference for Internet Search Engines Use to Locate Information on the Internet}

The analysis of the data pertaining to this issue is shown in table 3

Table 3. Search engines researchers prefer to use to locate information.

\begin{tabular}{llll}
\hline \multirow{2}{*}{ S/No } & Internet Search Engines & Responses & \\
\cline { 3 - 4 } & & Freq & \% \\
\hline 1 & Google & 88 & 100 \\
2 & Yahoo & 85 & 96.6 \\
3 & Alta Vista & 6 & 6.8 \\
4 & MSN & 12 & 13.6 \\
5 & Yandex & 9 & 10.2 \\
6 & Excite & - & - \\
7 & You tube & 47 & 53.4 \\
8 & Bing & 9 & 10.2 \\
9 & Ask & 5 & 5.9 \\
10 & Wikipedia & 21 & 23.9 \\
11 & Lycos & - & - \\
\hline
\end{tabular}

The table 3 above shows that $88(100 \%)$ of the respondents prefer to use Google to search for and locate information on the Internet, followed by Yahoo 85(96.6\%), and YouTube 47(53.4\%); meanwhile 21(23.9\%) indicates using Wikipedia; MSN 12(13.6\%); Yandex and Bing 9(10.2\%); Alta vista $6(6.8 \%)$ and Ask 5(5.9\%). From the analysis, it is observed that Google and Yahoo search engines are widely used as compared to other search engines because, information contained in these search engine is updated regularly; their links are provided to websites in the world; and they are fast in accessing information.

\subsection{Satisfaction Derived from Using the Internet by the Academic Staff}

The analysis of the data pertaining to this issue is shown in table 4

Table 4. Level of satisfaction derived from using the Internet by the academic staff.

\begin{tabular}{lll}
\hline Degree of Satisfaction & Frequency & Percentage \\
\hline Very Satisfied & 4 & 4.5 \\
Satisfied & 43 & 48.9 \\
Unsure & 3 & 3.4 \\
Dissatisfied & 29 & 33 \\
Very dissatisfied & 9 & 10.2 \\
\hline
\end{tabular}

Table 4 above shows the level of satisfaction with the use of Internet by academic staff in the libraries studied. From the analysis, it is found that a total of $4(4.5 \%)$ were very satisfied with the Internet resources/services provision; $43(48.9 \%)$ were satisfied, 3(3.4\%) were unsure, while $29(33 \%)$ were dissatisfied and $9(10.2 \%)$ were very dissatisfied.

\subsection{Challenges Encountered Using the Internet}

The analysis of the data pertaining to this issue is shown in table 5

Table 5. Challenges encountered using Internet Resources.

\begin{tabular}{llll}
\hline \multirow{2}{*}{ S/No } & Challenges & Responses & Percentage \\
\cline { 3 - 4 } & Slow Internet Service & Frequency & 93.2 \\
2 & Restriction of Access by library staff & - & - \\
3 & Erratic power supply & 17 & 19.3 \\
4 & Difficulty in finding relevant information & 14 & 15.9 \\
5 & Internet connection failure & 83 & 94.3 \\
6 & Inadequate number of connected system & 46 & 52.2 \\
7 & Unavailability of support for maintaining Internet facilities & 29 & 33 \\
\hline
\end{tabular}

From table 6 above, 83(94.3\%) of the respondents agree that Internet connection failure is one of the challenges to effective use of Internet service in the libraries studied. $82(93.2 \%)$ of the respondents indicates that slow Internet service is one of their major problem, $46(52.2 \%)$ of them are of the view that inadequate number of connected system is one of the impending factors. Also, 29(33\%) of the respondents are of the view that unavailability of support for maintaining Internet facilities is of a challenge to them; $17(19.3 \%)$ admits that erratic power supply is one of the problems to proper use of the Internet, and 14(15.9\%) indicates that difficulty in finding relevant information is a challenge to them, and none of the respondents see restriction of access by library staff as a challenge. This means that the major challenges faced by academic staff in their quest to use the Internet service in libraries studied is internet connection 
failure; slow internet service; inadequate number of connected system among others.

\section{Conclusion}

Based on the findings, the study concluded that academic staff of the institution uses e- mail service more than other internet services, because e-mail service is important for every researcher to communicate their ideas or thoughts among them and they can send digital files to others as attachment. The study equally revealed that majority of the academic staff makes use of the internet to search and obtain information for research and publication, send and receive email, access e-journals and other activities. The study also revealed that academic staff use Google and yahoo search engines more than others for their information search because their links are provided to websites in the world and also, they are fast in accessing information online. Furthermore, the study indicates that academic staffs are satisfied with the internet services provided though with some challenges such as internet connection failure, slow internet service, inadequate number of connected systems.

\section{Recommendation}

(1) Efforts should be made to increase the speed of the Internet access and shorten the time it takes to view and download web pages by providing more bandwidths.

(2) Management of the institution should install internet services that will connect all the offices of the academic staff. This will afford all academic staff irrespective of their status access to internet services.

(3) More recent models computers should be provided and be connected to internet facilities in the libraries for patrons use.

(4) A maintenance programme should be put in place for regular maintenance, up-grading and repairs.

\section{References}

[1] Gbaje, E. Shiloba (2007). Provision of online Information services in Nigeria Academic Libraries: Journal of Nigeria Library Association, Vol. 40.

[2] Agbaje, A. A. (2002): "Great Expectations: Serials Management and Information Technology" In: Madu, E. C. and Dirisu, M. B. (eds.). Information Science and Technology for Library School in Africa. Ibadan: Evi-Coleman Publications; p. $25-36$.

[3] Islam, Md. Maidul and Umme, Habiba (2015). Using pattern of Internet and E-resources by the students and faculty members of private University in Bangladesh. American Journal of Educational Research. 3(5) p.541-546.

[4] Nwagwu, M., Adekannbi, J. and Bello, O. (2009). Factors influencing use of the Internet: a questionnaire survey of the students of university of Ibadan, Nigeria. The Electronic Library. 27(4), 718-734.
[5] Ogunjobi, T. E. and Fagbami, O. O. (2012). Use of Internet by researchers in Agricultural research Institutes in Ibadan, Oyo State. International Journal of Library and Information Science 4(4), p.52-56.

[6] Ahmed, S. M. Z. (2013). Use of electronic resources by the faculty members in diverse public Universities in Bangladesh. The Electronic Library. 31(3), p. 290-312.

[7] Dirisu, M. B. (2000). "Special libraries and Information Technology" In: Madu, E. C. and Dirisu, M. B. (eds.). Information Science and Technology for Library Schools in Africa. Ibadan: Evi-Coleman Publications; p72-85.

[8] Omosekjimi, A. F., Ijiekhuamhen, O. P. and Emuejevoke, P. O. (2016). Accessibility and Use of Internet facilities in University Libraries: A study of Federal University of Petroleum Resources, Effurum. Middlebelt Journal of Library and Information Science 14. P.212-225.

[9] Muzakkari B. A (2002) Know the Internet. Lagos: Smark. p 1-10.

[10] Suleiman, I. and Aliyu, M. (2013). The use of Internet in teaching and research by academic staff of School of Management and Information Technology, Modibbo Adama University of Technology, Yola. The Information Manager 13(1\&2) p.59-68.

[11] Momani, H. A. (2007). 'Evaluation of the nature, extent, and satisfaction with the use of the Internet by applied science and technology faculty members in Jordan'. PhD Dissertation, University of Pittsburgh, Pitttsburgh, PA.

[12] Aliyu, M. (2011). The use of Internet by academic scientists in Modibbo Adama University of Technology, Yola. Samaru Journal of Information Studies. 11(1\&2). P. 1-4.

[13] Asemi, A. (2005). Information searching habits of Internet users: A case of the Medical Sciences University of Isfahan (MUI) Iran. Webology

2(1)http://www.webology.ir/2005/v2nl/a10.html\#9

[14] Monereo. C., Fuentes, M; \& Sanchez, S (2000) Internet search strategies used by experts and beginners Interactive Educational Multimedia, 1, 24-34(Electronic version). Retrieved September 15, 2012 fromhttp://www.ub.es/multimedia/iem/down/cl/Internetsearch and Navigation.pdf.

[15] Adesanya, O. (2002). The impact of Information technology on Information Dissemination. In: Madu C. E and Dirisu M. B. Information Science \&Technology for library School on Africa. Ibadan: Evi-Coleman Publications. P. 21.

[16] Madhusudhan, M. (2009). Internet use by research scholars in university of Delhi, India, Library Hi Tech News, 24(8) p.3642www.emeraldinsight.com/doi/.org/1108/07419050710836036

[17] Singh, N. (2001) Internet: Importance and usage for Library and Information Professionals. DESIDOC BUTTETIN of Information Technology, 21 (3) 18-2.

[18] Ojedokun, A. A. and Owolabi, E. O. (2010). Internet access competence and the use of internet for teaching and research activities by University of Botswana academic staff. African Journal of Library, Archives and Information Science. 13(1), 43-53.

[19] Al-Ansari, H. (2006). The Internet use by faculty members, Kuwait University. The Electronic Library, 26(6). 791-803. 
[20] Mohammed, H. K, (2007). Use of ICT based resources and services in special libraries in Kerala: Annals of library and Information studies, Vol. 54 PP. 23-30.

[21] Oketunji, I. (2001). Agenda for putting Information Technology to work in Nigerian Librarians in the New Millenium. In Library and Information Agenda for the New Millenium: A Compendium of Paper presentations at the 2000 NLA Annual Conference and AGM.

[22] Aqil, M. and Ahmed, P. (2011). Use of Internet by research scholars and postgraduate students of the science faculty of Aligarh Muslim University. Library Philosophy and Practice, paper 538. Available athttp://digitalcommons.unl.edu/libphiprac/538

[23] Salaam, M. O. (2008). A survey of the use of Internet services in Nigeria University Libraries. Assets series A 3(3) p 115121.

[24] Ishola et al (2016), Availability, accessibility and use of eresources in selected private universities in South West, Nigeria. Middlebelt Journal of Library and Information Science, 14(1) 160.

[25] Nwokedi, V. C. (2007). Impact of Internet use on teaching and research activities of the academic staff of faculty of medical sciences, University of Jos: A case study. Gateway Library Journal 10(1) p 13-22.

[26] Osuala, E. C. (2007) Introduction to Research Methodology. Onitsha: African Publishers.

[27] Akuezilo, E. O. (1993). Research Methodology. Nuel Centi: Enugu. 